\title{
Joint Effect of the Nonlinearity of Elastic Foundations and the Variation of the Inertia Ratio on Buckling Behavior of Prismatic and Nonprismatic Columns Using a GDQ Method
}

\author{
Ramzy M. Abumandour (D), ${ }^{1}$ Fathi A. Abdelmgeed, ${ }^{2}$ and Adel M. Elrefaey ${ }^{3}$ \\ ${ }^{1}$ Basic Engineering Sciences Department, Faculty of Engineering, Menoufia University, Shibin Al Kawm, Egypt \\ ${ }^{2}$ Department of Civil Engineering, Faculty of Engineering, Kafrelsheikh University, Kafr El-Sheikh, Egypt \\ ${ }^{3}$ College of engineering and Technology, Arab Academy for Science, Technology and Maritime Transport, Alexandria, Egypt
}

Correspondence should be addressed to Ramzy M. Abumandour; ramzy_0000@yahoo.com

Received 2 August 2019; Revised 27 September 2019; Accepted 10 December 2019; Published 25 January 2020

Academic Editor: Fiorenzo A. Fazzolari

Copyright (c) 2020 Ramzy M. Abumandour et al. This is an open access article distributed under the Creative Commons Attribution License, which permits unrestricted use, distribution, and reproduction in any medium, provided the original work is properly cited.

\begin{abstract}
In this paper, we present a simple, powerful, yet efficient and easily applicable technique based on the GDQ method for solving nonlinear problems. The proposed technique is implemented to some nonlinear engineering problems in structure analysis. The results reveal that the proposed technique is effective. Then, the proposed technique is used to explain the effects of the variation of cross section area on the nondimensional critical buckling loads for columns with and without elastic foundation for three sets of boundary conditions. Finally, the proposed technique is used to investigate the effect of the nonlinearity term of Winkler elastic foundation on the nondimensional critical buckling loads of nonuniform columns resting on elastic foundations. The effectiveness of the proposed technique is validated through comparing the present results with exact solutions and other numerical results available in references. The proposed method benefits the optimum design of columns against buckling in engineering applications. The most important conclusions from this paper can be summarized as follows. When the inertia ratio varies parabolically, the nondimensional critical buckling loads increase in comparison with varying linearly. Moreover, the nondimensional critical buckling loads increase in the presence of the elastic foundation.
\end{abstract}

\section{Introduction}

It is pivotal in structural analysis and its design to study the buckling behaviors and to determine the critical buckling loads for uniform and nonuniform structural members.

Many types of structures and structural members for buckling analysis can be defined as a uniform and/or nonuniform with different end conditions widely used as columns in many engineering structure applications such as but not limited to columns, shells and plates, cranes, and other application fields. One of the very important branches of studied in the fields of structural, mechanical engineering, and aeronautical engineering is the buckling analysis of nonuniform columns. So, this field has become more and more systematic during the last decades. This field has become the focal point of many researchers and studies. Several researchers have studied the buckling analysis of nonuniform columns that are closely related to the fields of structural, mechanical, and aeronautical engineering. Until now, a great deal of literature has been published on investigating the buckling of nonuniform columns. This is mainly due to the fact that it may provide an economical solution to carry the desired higher compressive loads in engineering structures.

In 1778, Leonard Euler determined the critical buckling of columns under effect of axial compressive forces in statics [1]. In this field, after Euler study, Swenson [2] studied the nonuniform beams and columns using a simple DC network analyzer, and Chajes [3] presented in his book the principles of structural stability. Greenhill [4] made adept 
contributions to the field through his study of the exact analytical solution for the buckling problem of a nonuniform column with arbitrary distributions of flexural stiffness and axial distributed forces difficult to establish. A summary of the solutions for some simple cases by several researchers are shown in Coşkun [5].

On the other hand, the closed-form solution of the $4^{\text {th }}$ order differential equation governing for the buckling or vibration behavior of columns or beams with arbitrary distributions of flexural stiffness and different end conditions is very difficult to determine in most of the cases and exists only for limited cases. In addition to this research field, several researchers presented some exact solutions to study the buckling of nonuniform columns, in terms of logarithmic and trigonometric functions, Bessel functions, Lommel functions, and in terms of series representation shown by Erylmaz et al. [6]. During the last decades, the columns' buckling has become the center point of study for many researchers. In addition, studying the columns' buckling has already become more and more systematic. Later on, analytical approximate techniques were used for the stability analysis of elastic columns and introduced an exact analytical solution for buckling analysis of non-uniform columns presented by Coşkun and Öztürk [7]. Early studies on the stability of finite columns resting on nonlinear elastic foundations with certain prescribed boundary conditions have been presented by Taha and Abohadima [8], Coşkun and Atay [9, 10], Singh and Li [11], and Huang and Li [12] for determining critical loads of nonuniform columns.

The investigations of elastic buckling load and natural frequency of structure members resting on elastic foundations are also one of the complicated and significant problems in many component designs related to soilstructure interaction such as the foundation of buildings, the pipelines embedded in soil, highway pavements, and the like. In modern engineering problems of structural design, structures on elastic foundations have wide applications. In elastic foundation, the elastic media can be defined by an equally spaced elastic supports of equal rigidity. At any cross section of the bar, the reaction of the medium is proportional to the deflection at that section. In this regard, different types of elastic foundation models like Winkler, Pasternak, and Vlasov were presented. In the case of the Winkler foundation model, reaction forces are proportional to the deflection of a beam at each point of contact and the foundation characteristics are modeled by adopting the system of fixed linear springs. The constant of proportionality of these springs is defined by the foundation modulus, also, known as the subgrade modulus. The Winkler type of foundation is extensively used in practice for solving the problems mentioned above. In this model, the elastic foundation by Winkler's theory was inadequate in different problems since this model overlooks the soil cohesion. In order to improve this weakness, any two-parameter elastic foundation models were developed such as the Winkler-Pasternak foundation. In this model, an additional layer is considered in the widely used Winkler model to accomplish the effect of shear interactions between the springs. Closed-form solutions to some simple problems of beams on elastic foundation proposed by numerous authors are shown in Yankelevsky et al. [13].

An important study for some different types of elastic foundation models as, Winkler, Pasternak, Vlaslov, Filonenko-Borodich presented by Kerr [14] in his paper. Later on, some researchers studied the buckling analysis of beams or columns resting on elastic foundations using different methods such as Eisenberger and Clastornik [15], Malekzadeh and Karami [16], Coşkun and Atay $[9,10]$, and Coşkun $[5,17]$. Some problems studied in structural analysis and free vibration of uniform and nonuniform beams resting on fluid layer using GDQ method are presented by Abumandour et al. [18, 19]. Also, Abumandour et al. [20, 21] used a new hybrid technique combining GDQM and Newton's method to study the free vibration analysis and determine the deflection of nonuniform beams resting on two nonlinear elastic foundations subjected to axial and transverse distributed force.

In engineering applications, the nonlinear elastic foundations provide a simplified model for various complex or complicated nonlinear systems. The nonlinearity sources and the classification were later studied by Kerschen et al. [22] and Afsharfard and Farshidianfar [23]. In his books, Nayfeh [24, 25] presented the weak nonlinear problems. Some researchers used the perturbation techniques to study many cases of the nonlinearity problems of structure analysis. Nowadays, some researchers are interested in using analytical or numerical techniques to solve nonlinear problems. This is mainly due to the fact that every physical problem is really nonlinear problem which means that it should be described using nonlinear equations. However, the analytical solution of nonuniform columns or beams needs the solution of differential equations with variable coefficients, so it is very hard work. There are many numerical and semianalytical methods; however, some analytical methods were developed to obtain approximate solutions for the static and dynamic behavior of non-uniform beams by several researchers and are shown in Coşkun and Öztürk [7] and Adair et al. [26].

The proposed technique presented is based on the GDQM to solve the nonlinear problems. The GDQ method has been applied successfully in our team work for solutions of a variety of problems such as in fluid mechanics $[27,28]$ and structural analysis $[18,21]$. In addition, several researchers are interested in other various problems such as Chen and Cheung [29], Fung [30, 31], Shu et al. [32], and Liu and Wang [33]. A year later, Malekzadeh and Karami [16] exploited a mixed differential quadrature and the finite element method to study the vibration and buckling behaviors of beam-like structures on elastic foundations. Abumandour et al. $[20,21]$ presented an approach combining the GDQ method with Newton's method to study the free vibration analysis and determine the deflection of nonuniform beams resting on two nonlinear elastic foundations subjected to axial and transverse distributed force. 
In this paper, we present three objectives. The first objective is to introduce a proposed technique of GDQ method for solving nonlinear problems. The second objective is to apply a proposed technique of GDQ method in determining the nondimensional critical buckling loads of uniform and nonuniform columns resting on the two-layer elastic foundations (linear and nonlinear Winkler elastic foundation and the linear Pasternak elastic foundation). In addition, the paper explains the effects of the varying cross section area on the nondimensional critical buckling loads for columns with and without elastic foundation for three sets of boundary conditions, with different stiffness distributions. Finally, the third objective is to investigate the effect of the nonlinearity term of Winkler elastic foundation on the nondimensional critical buckling loads of nonuniform columns resting on elastic foundations (linear and nonlinear Winkler (normal) foundation and linear Pasternak (shear) foundation), under the three sets of boundary conditions. The validation of the proposed method has been approved by comparing our numerical results with the exact solutions and other available numerical results of uniform and nonuniform columns.

\section{Problem Formulations and Mathematical Analysis}

Consider a nonuniform column of finite length $L$ and width $b$ with flexural rigidity EI, as shown in Figure 1. The column resting on a Winkler-Pasternak elastic foundation (linear $k_{1}$ and nonlinear $k_{2}$ Winkler normal stiffnesses and the linear Pasternak shear stiffnesses $k_{3}$ ) continuously restrained along its length subjected to axial load $p(x, t)$ and transverse load $F(x, t)$. The cross section is assumed to vary continuously along the axial direction.

Based on the Euler-Bernoulli beam theory, the governing differential equations of buckling of nonuniform columns resting on nonlinear Winkler-Pasternak elastic foundation are

$$
\begin{gathered}
\frac{\partial^{2}}{\partial x^{2}}\left(E I \frac{\partial^{2} v}{\partial x^{2}}\right)+\rho A \frac{\partial^{2} v}{\partial t^{2}}+p \frac{\partial^{2} v}{\partial x^{2}}+k_{1} v+k_{2} v^{3} \\
-k_{3} \frac{\partial^{2} v}{\partial x^{2}}=F(x, t), \quad 0 \leq x \leq L,
\end{gathered}
$$

where $v(x, t)$ is the flexural deflection, $\rho$ is the density of the beam material, $A(x)$ is the area of the beam section, $E(x)$ is Young's modulus, $I(x)$ is the moment of inertia, $p(x, t)$ is the axial force, $k_{1}$ is the linear Winkler foundation parameter, $k_{2}$ is the nonlinear Winkler foundation parameter, and $k_{3}$ is the linear Pasternak foundation parameter.

General case of column buckling is shown in Figure 2. The geometry, the loading conditions, and the effect of end conditions on the column are shown in Figure 3.

The corresponding boundary conditions along the $x=0$ and $L$ edges are as follows:

For clamped-clamped supported (C-C):

$$
\text { At } \mathbf{x}=0 \text {, }
$$

$$
W(0)=\frac{\mathrm{d} W(0)}{\mathrm{d} x}=0,
$$

At $\mathbf{x}=\mathbf{L}$,

$$
W(L)=\frac{\mathrm{d} W(L)}{\mathrm{d} x}=0 .
$$

For simply-simply supported (S-S):

At $\mathbf{x}=0$,

$$
W(0)=\frac{\mathrm{d}^{2} W(0)}{\mathrm{d} x^{2}}=0 .
$$

At $\mathbf{x}=\mathbf{L}$,

$$
W(L)=\frac{\mathrm{d}^{2} W(L)}{\mathrm{d} x^{2}}=0 .
$$

For clamped-simply supported (C-S):

At $\mathbf{x}=0$,

$$
W(0)=\frac{\mathrm{d} W(0)}{\mathrm{d} x}=0,
$$

At $\mathbf{x}=\mathbf{L}$,

$$
W(L)=\frac{\mathrm{d}^{2} W(L)}{\mathrm{d} x^{2}}=0
$$

To obtain the buckling loads, assume the solution of equation (1) to be

$$
v(x, t)=V(x) e^{i \omega t},
$$

where the amplitude of free vibration is $V(x)$ and the natural frequency of the column is $\omega$. Substituting equation (8) into equation (1) yields

$$
\begin{aligned}
& \frac{\mathrm{d}^{2}}{\mathrm{~d} x^{2}}\left(E I \frac{\mathrm{d}^{2} V}{\mathrm{~d} x^{2}}\right) e^{i \omega t}+\rho A V \omega^{2} e^{i \omega t}+p \frac{\mathrm{d}^{2} V}{\mathrm{~d} x^{2}} e^{i \omega t} \\
& \quad+k_{1}\left(V e^{i \omega t}\right)+k_{2}\left(V^{3} e^{3 i \omega t}\right)-k_{3} \frac{\mathrm{d}^{2} V}{\mathrm{~d} x^{2}} e^{i \omega t}=0, \quad 0 \leq x \leq L,
\end{aligned}
$$

$$
\begin{aligned}
& \frac{\mathrm{d}^{2}}{\mathrm{~d} x^{2}}\left(E I \frac{\mathrm{d}^{2} V}{\mathrm{~d} x^{2}}\right)+\rho A V \omega^{2}+p \frac{\mathrm{d}^{2} V}{\mathrm{~d} x^{2}}+k_{1} V+k_{2}\left(V^{3} e^{2 i \omega t}\right) \\
& \quad-k_{3} \frac{\mathrm{d}^{2} V}{\mathrm{~d} x^{2}}=0, \quad 0 \leq x \leq L .
\end{aligned}
$$

For static deflection:

The inertia term is neglected and (10) becomes 


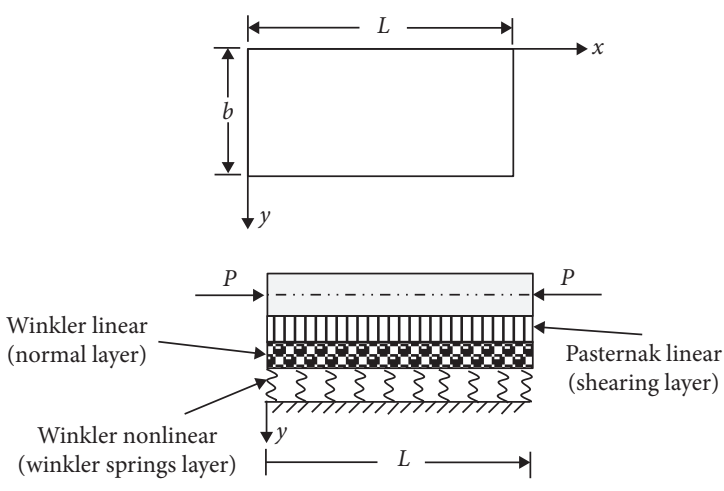

(a)

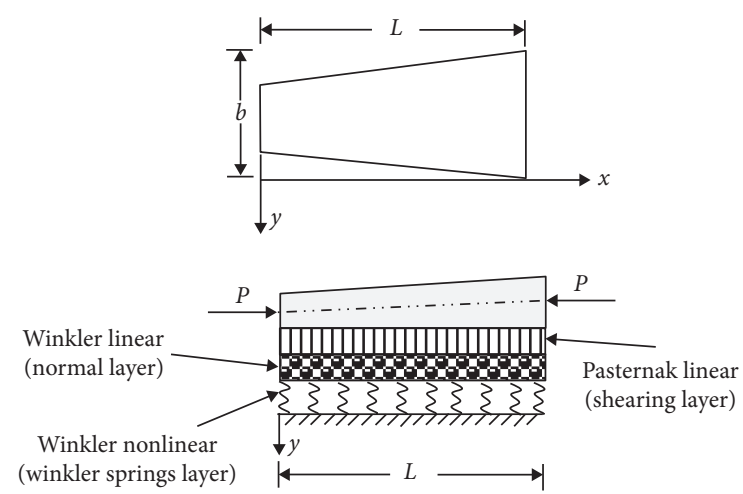

(b)

FIGURE 1: (a) Geometry of uniform columns resting on two elastic foundations under axial and transverse load. (b) Geometry of nonuniform columns on two elastic foundations under axial and transverse load.

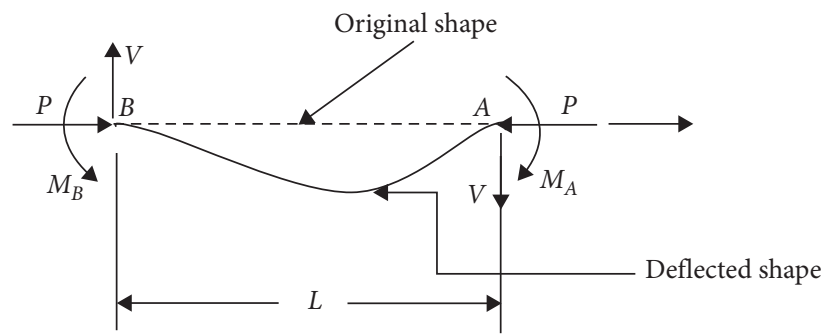

FIGURE 2: General case of column buckling.

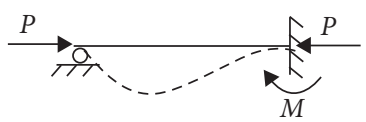

(a)

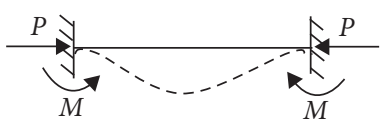

(b)

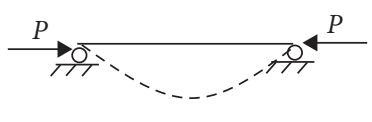

(c)

Figure 3: Three end conditions for classical Euler column. (a) For clamped-simply supported column (fixed/pinned ends). (b) For clampedclamped supported column (fixed ends). (c) For simply-simply supported column (pinned ends).

$$
\frac{\mathrm{d}^{2}}{\mathrm{~d} x^{2}}\left(E I \frac{\mathrm{d}^{2} V}{\mathrm{~d} x^{2}}\right)+p \frac{\mathrm{d}^{2} V}{\mathrm{~d} x^{2}}+k_{1} V+k_{2} V^{3}-k_{3} \frac{\mathrm{d}^{2} V}{\mathrm{~d} x^{2}}=0, \quad 0 \leq x \leq L
$$

Equation (11) can be transformed to a nondimensional form as follows:

$$
\begin{gathered}
S(X) \frac{\mathrm{d}^{4} W}{\mathrm{~d} X^{4}}+2 \frac{\mathrm{d} S(X)}{\mathrm{d} X} \frac{\mathrm{d}^{3} W}{\mathrm{~d} X^{3}}+\frac{\mathrm{d}^{2} S(X)}{\mathrm{d} x^{2}} \frac{\mathrm{d}^{2} W}{\mathrm{~d} X^{2}}+K_{1} W \\
+K_{2} W^{3}-K_{3} \frac{\mathrm{d}^{2} W}{\mathrm{~d} X^{2}}+\lambda \frac{\mathrm{d}^{2} W}{\mathrm{~d} X^{2}}=0, \quad 0 \leq X \leq 1,
\end{gathered}
$$

The nondimensional coefficients are $W=V / L, X=x / L, \lambda=$ $P L^{2} / E I_{0}, K_{1}=k_{1} L^{4} / E I_{0}, K_{2}=k_{2} L^{6} / E I_{0}, K_{3}=k_{3} L^{2} / E I_{0}$, and $S(X)=E I(x) / E I_{0}$, where $W$ is the nondimensional deflection of the column, $P$ is the nondimensional axial loading, $K_{1}$ is the nondimensional linear Winkler (normal) foundation parameter of foundation, $K_{2}$ is the nondimensional nonlinear Winkler (normal) foundation parameter of foundation, $K_{3}$ is the nondimensional linear
Pasternak (shear) foundation parameter of foundation, the column's flexural rigidity is $E I(X)$, the inertia ratio is $S(X)$, and $\lambda$ is the nondimensional buckling load of the column.

Equation (12) is a $4^{\text {th }}$ order ordinary differential equation with varying cross section area (inertia ratio). Next, we introduce an overview of the method of solution (generalized differential quadrature method).

\section{GDQ Method Review}

The DQ method, introduced by Bellman et al. [34, 35], is a numerical technique for solving initial as well as boundary value problems. Bert and his coworkers first used the DQ method to solve problems in structural mechanics in [36]. Bellman et al. [34] suggested two methods to determine the weighting coefficients of the first order derivative. For more details of the DQM and its applications, see [37, 38]. More generally, Shu et al. in $[39,40]$ presented the generalized differential quadrature (GDQ) and applied it to solve some fluid dynamics problems. 
The dimensionless differential governing equation of column (12) can be transformed into a system of algebraic equations by using the GDQ method [40]. The essence of this method is that it is used to approximate the derivatives of the function $W(X)$ by a weighted linear summation of all the functional values $W\left(X_{i}\right)$ along the computational (discretized) domain. The $k^{\text {th }}$-order derivative of the solution function at grid point $i$ in one dimension is expressed by the differential quadrature rule as

$$
f_{x}^{(k)}\left(X_{i}\right)=\left.\frac{\mathrm{d}^{(k)} f}{\mathrm{~d} x^{(k)}}\right|_{x_{i}}=\sum_{j=1}^{N} C_{i j}^{(k)} f\left(x_{j}\right), \quad \text { for } i=1,2,3, \ldots, N,
$$

where $N$ is the total number of the sampling grid points distribution chosen in the whole domain and $C_{i j}^{(k)}$ are the weighting coefficients for the $k^{\text {th }}$ order derivative at the $i^{\text {th }}$ sampling point. It should be noted that the weighting coefficients $C_{i j}^{(k)}$ are different at different locations of $x_{i}$.

From equation (13), we can realize that the key to GDQ method is how to determine the weighting coefficients for the discretization of a derivative of any order and choose the grid points. It means that the weighting coefficients depend on the order of derivative and on the number of the sampling points (spatial grid spacing) along the domain.

The formula for determining the weighting coefficients can be calculated by using Lagrange interpolation formula as follows [37, 40]:

$$
\begin{aligned}
& g_{k}(x)=\frac{M(x)}{\left(x-x_{k}\right) M^{(1)}\left(x_{k}\right)}, \quad \text { where } k=1,2,3, \ldots, N \\
& M(x)=\left(x-x_{1}\right)\left(x-x_{2}\right) \cdots\left(x-x_{N}\right),
\end{aligned}
$$$$
M^{(1)}\left(x_{i}\right)=\prod_{k=1, k \neq i}^{N}\left(x_{i}-x_{k}\right) .
$$

By applying equation (14) at $N$ grid points, they obtained the following algebraic formulations to compute the weighting coefficients $A_{i j}$. For the first derivative, the weighting coefficients are calculated as follows:

$$
\begin{aligned}
A_{i j} & =\frac{1}{x_{i}-x_{j}} \prod_{k=1, k \neq i, j}^{N} \frac{\left(x_{i}-x_{k}\right)}{\left(x_{j}-x_{k}\right)}, \quad j \neq i, \\
A_{i i} & =\prod_{k=1, k \neq i}^{N} \frac{1}{x_{i}-x_{k}} .
\end{aligned}
$$

After calculating the weighting coefficients of first-order derivatives, the weighting coefficients of higher-order derivatives can be easily determined by simple matrix multiplication which is given as

$$
\begin{aligned}
{\left[C^{(k)}\right]=\left[C^{(1)}\right]\left[C^{(k-1)}\right]=\left[C^{(k-1)}\right]\left[C^{(1)}\right], } \\
\quad k=2,3,4, \ldots, N-1 .
\end{aligned}
$$

The accuracy of the results obtained by DQM is affected by choosing the number of grid points, $N$, and the type of sampling points, $X_{i}$. It is found that the optimal selection of the sampling points in structure problems, according to Gauss-Chebyshev-Lobatto points, is as follows [41]:

$$
X(i)=\frac{1}{2}\left[1-\cos \left(\frac{i-1}{N-1}\right) \pi\right], \quad i=1,2,3, \ldots, N .
$$

\section{Discretized Equations and Numerical Implementation}

4.1. GDQ Discretized for the Governing Equations of the Column. The GDQ techniques illustrated in the above section 3 can be used to rewrite the differential governing equations into a system of algebraic equations by transforming every space derivative of the dependent variable into the weighted sum of node values as follows:

$$
\begin{array}{r}
S(X)\left(\sum_{j=1}^{N} D_{i j} W_{j}\right)+2 S^{(1)}\left(X_{i}\right)\left(\sum_{j=1}^{N} C_{i j} W_{j}\right) \\
+S^{(2)}\left(X_{i}\right)\left(\sum_{j=1}^{N} B_{i j} W_{j}\right)+K_{1} W_{i}+K_{2} W_{i}^{3} \\
-K_{3}\left(\sum_{j=1}^{N} B_{i j} W_{j}\right)+\lambda\left(\sum_{j=1}^{N} B_{i j} W_{j}\right)=0, \\
i=1,2,3, \ldots, N,
\end{array}
$$

where $W_{i}, i=1,2, \ldots, N$, is the functional value at the grid $X_{i}, B_{i j}, C_{i j}$, and $D_{i j}$ are the weighting coefficient matrix of the second-, third-, and fourth-order derivatives, and $S^{(1)}\left(X_{i}\right)$ and $S^{(2)}\left(X_{i}\right)$ are the second- and first-order derivatives of $S(X)$ at $X_{i}$.

4.2. Implementation of Boundary Conditions. Various boundary conditions can be directly implemented by substituting the governing equations using the substitutions of the boundary conditions into the governing equations (SBCGE) method. Then, the problem is simplified to the eigenvalue equation system. The essence of the SBCGE is that the Dirichlet condition is implemented at the boundary points, while the derivative condition is discretized by the GDQ method, a technique referred to as SBCGE [42-44].

The derivatives in the boundary conditions given by equations (2) through (7) can be discretized by the GDQ method. As a result, the numerical boundary conditions can be written as

$$
\begin{aligned}
W_{1} & =0, \\
\sum_{k=1}^{N} C_{1 k}^{(n 0)} W_{k} & =0, \\
W_{N} & =0, \\
\sum_{k=1}^{N} C_{N k}^{(n 1)} W_{k} & =0,
\end{aligned}
$$


where $n 0$ and $n 1$ may be taken as either 1 or 2 . By choosing the value of $n 0$ and $n 1$, equations (21) through (24) can give the following four sets of boundary conditions:

$$
\begin{aligned}
& n 0=1, n 1=1 \text {-clamped }- \text { clamped sup ported } \\
& n 0=1, n 1=2-\text { clamped }- \text { simply supported } \\
& n 0=2, n 1=1-\text { simply }- \text { clamped supported } \\
& n 0=2, n 1=2-\text { simply }- \text { simply supported }
\end{aligned}
$$

Equations (21) and (23) can be easily substituted into the governing equation. We can couple equations (22) and (24) together to give two solutions, $W_{2}$ and $W_{N-1}$, as

$$
\begin{aligned}
W_{2} & =\frac{1}{\mathrm{AXN}} \sum_{k=1}^{N} \mathrm{AXK} 1 \cdot W_{k}, \\
W_{N-1} & =\frac{1}{\mathrm{AXN}} \sum_{k=1}^{N} \mathrm{AXKN} \cdot W_{k},
\end{aligned}
$$

where $\quad \mathrm{AXN}=C_{1, N-1}^{(n 0)} C_{N, 2}^{(n 1)}-C_{1,2}^{(n 0)} C_{N, N-1}^{(n 1)}, \quad \operatorname{AXK} 1=C_{1, k}^{(n 0)}$ $C_{N, N-1}^{(n 1)}-C_{1, N-1}^{(n 0)} C_{N, k}^{(n 1)}$, and $\quad \mathrm{AXKN}=C_{1,2}^{(n 0)} C_{N, k}^{(n 1)}-C_{1, k}^{(n 0)}$ $C_{N, 2}^{(n 1)}$. Equations (25) and (26) for $W_{2}$ and $W_{N-1}$ are expressed in terms of $W_{3}, W_{4}, \ldots, W_{N-2}$, and then can be easily substituted into the discrete governing equation (20) which is applied to the interior points $2 \leq i \leq N-2$. In order to close the system, the discretized governing equation (20) has to be applied at $(N-4)$ mesh points. The dimension of the equation system using this approach is $(N-4) \times(N-4)$.

$$
\begin{array}{r}
S(X)\left(\sum_{j=3}^{N-2} D_{i j} W_{j}\right)+2 S^{(1)}\left(X_{i}\right)\left(\sum_{j=3}^{N-2} C_{i j} W_{j}\right) \\
+S^{(2)}\left(X_{i}\right)\left(\sum_{j=3}^{N-2} B_{i j} W_{j}\right)+K_{1} W_{i}+K_{2} W_{i}^{3} \\
-K_{3}\left(\sum_{j=3}^{N-2} B_{i j} W_{j}\right)+\lambda\left(\sum_{j=3}^{N-2} B_{i j} W_{j}\right)=0, \\
i=3,4, \ldots, N-2 .
\end{array}
$$

Equations (27) has $(N-4)$ equations with $(N-4)$ unknowns, which can be written as

$$
[A]\{W\}+K_{2}\left\{W^{3}\right\}=\lambda[B]\{W\},
$$

where, $\{W\}=\left\{W_{3}, W_{4}, \ldots, W_{N-2}\right\}^{T}$.

\section{Numerical Results and Discussion}

In this section, the studies have been presented for investigating the buckling behaviors of nonuniform columns resting on two-layer elastic (Winkler (linear and nonlinear) and Pasternak) foundations under axial compression with different boundary conditions using a new hybrid approach of GDQ method. Moreover, the studies have been presented for investigating the buckling behaviors of the nonuniform columns under the effect of the linear $\left(k_{1}\right)$ and nonlinear $\left(k_{2}\right)$ Winkler (normal) foundation parameters and the linear Pasternak (shear) foundation parameter.

The GDQ method is used to compute the critical buckling load with two cases of inertia ratio $S(X)=\left(1+\alpha_{1} X\right)^{\alpha_{2}}$ (the first case: $\left(\alpha_{1}=1.0\right),\left(\alpha_{2}=1.0\right)$ and the second case: $\left.\left(\alpha_{1}=1.0\right),\left(\alpha_{2}=2.0\right)\right)$, with three different types of end conditions.

5.1. Validation of the Solution Technique. In order to examine the effectiveness and convergence of the proposed technique, we have determined the critical buckling loads $(\lambda)$ for a uniform and nonuniform column subjected to axial compression force, under the three sets of boundary conditions: clamped-clamped (c-c) supported, simply-simply (s-s) supported and clamped-simply (C-S) supported, respectively.

The first validation, for uniform columns, i.e., the inertia ratio $S(X)=1$, the numerical results are tabulated in Table 1 together with the exact solution presented by Chajes [3], numerical results using the GDQ presented by Du et al. [45], numerical results using GDQ with SBCGE presented by Ramzy et al. [19], and numerical results using FEM presented by Newberry [46] for various end supports are applied to validate the proposed technique.

By comparing the exact solution and other numerical results with our numerical results of the proposed technique, it is clear that the proposed technique has a rapid convergence and is in very good accordance with the existing numerical results shown in Table 1 . In our results, when the number of grid point $(N)$ reaches $N=11$, the errors between our numerical results and exact solution are identical to the exact solution up to 15 decimal digits; it means that the proposed technique of GDQ approach is very efficient.

The absolute relative error type in Table 1 represents the accuracy of the proposed technique. This absolute relative error can be defined by the formula |((PresentExact)/Exact) $\times 100 \mid$.

Figures 4-6 show the first three mode shapes of the uniform column for three types of end supports which results from the proposed technique of the GDQM with SBCGE, respectively.

The second validation for nonuniform columns is to study the effect of the varying cross section area (the inertia ratio (stiffness distributions)), by taking two special cases of the stiffness distributions as polynomials of the form $S(X)=\left(1+\alpha_{1} X\right)^{\alpha_{2}}$ : the first case being linearly varying of the inertia ratio $\left[\alpha_{1}=1.0, \alpha_{2}=1.0\right]$, i.e., $[S(X)=(1+X)]$, and the second case being parabolically varying of the inertia ratio $\left[\alpha_{1}=1.0, \alpha_{2}=2.0\right] S(X)=(1+X)^{2}$. Our numerical results are tabulated in Tables 2 and 3 , by using number of grid points $(N=11)$ together with other numerical results presented by Swenson [2], Bleich [47], Bert [48], Du et al. [45], and Ramzy et al. [19], various end supports are applied to validate the proposed technique. Tables 2 and 3 demonstrate that the present critical buckling loads are in very good agreement with the existing numerical results. 
TABLE 1: Nondimensional critical buckling loads of uniform columns for various end supports.

\begin{tabular}{|c|c|c|c|c|c|c|}
\hline \multirow{2}{*}{$\begin{array}{l}\text { Boundary } \\
\text { conditions }\end{array}$} & \multicolumn{6}{|c|}{ Buckling load $(\lambda)$} \\
\hline & $\begin{array}{l}\text { Exact solution } \\
\text { (Chajes [3]) }\end{array}$ & $\begin{array}{l}\text { GDQ }(N=11) \\
\text { (Du et al. }[45])\end{array}$ & $\begin{array}{c}\text { FEM (Newberry } \\
\text { et al. [46]) }\end{array}$ & $\begin{array}{c}\operatorname{SBCGM}(N=11) \\
\text { (Abumandour et al. }[21])\end{array}$ & $\begin{array}{l}\text { Present proposed } \\
\text { technique }(N=11)\end{array}$ & $\begin{array}{c}\text { Absolute } \\
\text { relative error \% }\end{array}$ \\
\hline Simply-simply & 9.8696 & 9.8696 & 9.9438 & 9.8696 & 9.8696 & 0.00000 \\
\hline $\begin{array}{l}\text { Clamped- } \\
\text { clamped }\end{array}$ & 39.4784 & 39.4784 & 39.9730 & 39.4784 & 39.4784 & 0.00000 \\
\hline $\begin{array}{l}\text { Clamped- } \\
\text { simply }\end{array}$ & 20.1907 & 20.19072 & 20.4972 & 20.1907 & 20.1907 & 0.00000 \\
\hline
\end{tabular}

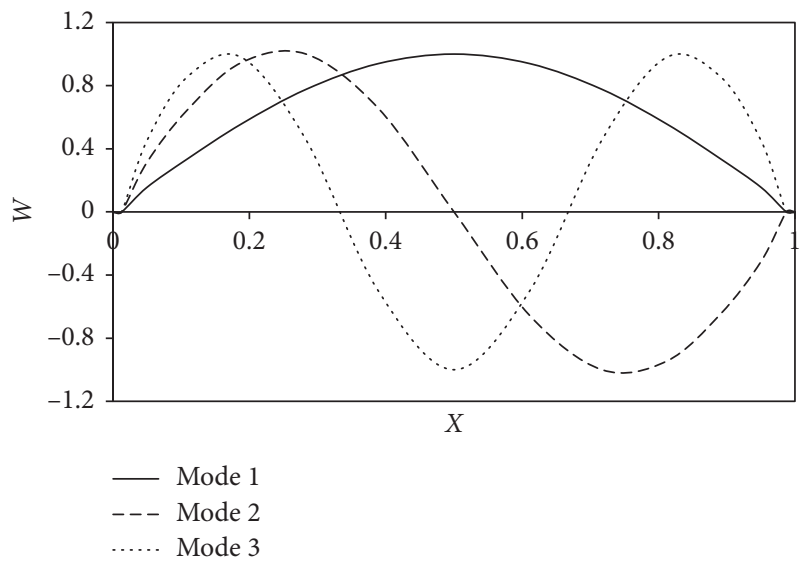

FIGURE 4: The first three mode shapes of uniform simply-simply supported column.

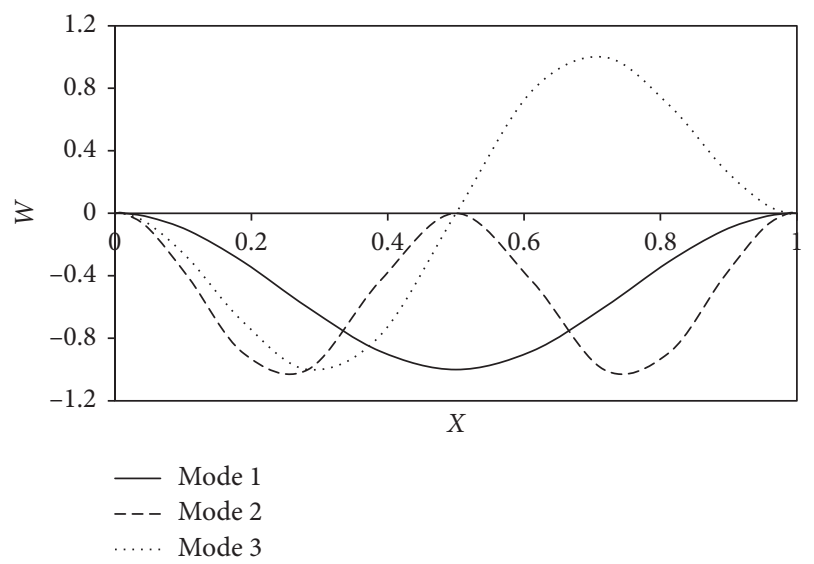

FIGURE 5: The first three mode shapes of uniform clamped-clamped supported column.

Other validation for the above case (for nonuniform columns) in order to investigate the effect of the varying of cross section area, by taking the same two special cases of the stiffness distributions as a polynomial of the form $S(X)=\left(1+\alpha_{1} X\right)^{\alpha_{2}}$; the first case being linearly varying of the inertia ratio $[S(X)=(1+X)]$, and the second case being parabolically varying of the inertia ratio $\left[S(X)=(1+X)^{2}\right]$, without elastic foundations, respectively. Our numerical results are tabulated in Tables 4 and 5, by using number of grid points $(N=15)$ together with other numerical results, by

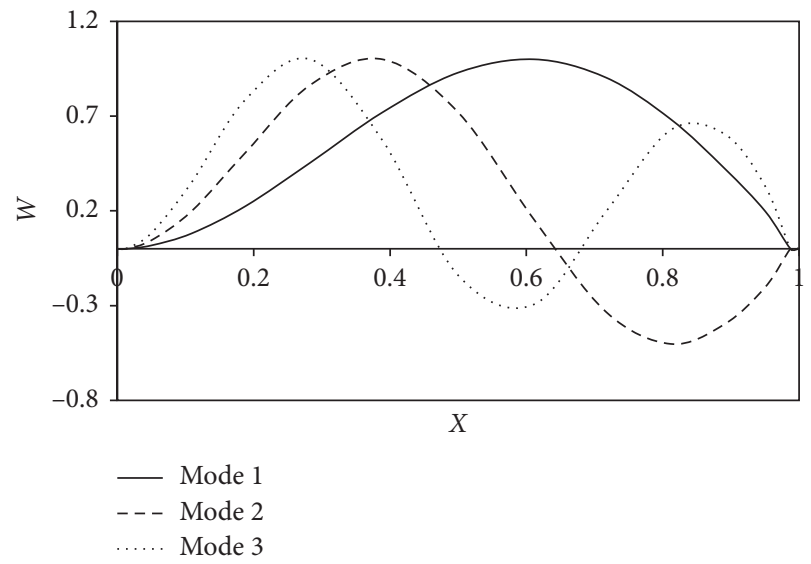

FIGURE 6: The first three mode shapes of uniform clamped-simply supported column.

an improved version of the Rayleigh technique Bert [48], the stiffness matrix method Eisenberger [49], a low dimensional mathematical model Singh and Li [11], Rayleigh's quotient method Rosa and Franciosi [50], a new and simple approach Huang and Luo [51]. From Tables 4 and 5, it is clear that our results are very compatible with their results. Our results are nearly identical to the results obtained by Huang and Luo [51] and Eisenberger [49].

5.2. Results Using a Proposed Technique of GDQM. In order to investigate the effect of the nonlinearity term of Winkler elastic foundation on the nondimensional critical buckling loads of nonuniform columns resting on twolayer elastic foundations (linear and nonlinear Winkler (normal) foundation and linear Pasternak (shear) foundation), under the three sets of boundary conditions, we study the effect of the varying cross section area (the inertia ratio (stiffness distributions)) by taking two special cases of the stiffness distributions as polynomials of the form $S(X)=\left(1+\alpha_{1} X\right)^{\alpha_{2}}$ : the first case $\left[\alpha_{1}=1.0, \alpha_{2}=1.0\right]$, i.e., $[S(X)=(1+X)]$, being linearly varying of the inertia ratio, and the second case $\left[\alpha_{1}=1.0, \alpha_{2}=2.0\right]$, i.e., $\left[S(X)=(1+X)^{2}\right]$, being parabolically varying of the inertia ratio, respectively.

Our numerical results are tabulated in Tables 6 and 7, by using number of grid points $(N=15)$ and the nondimensional critical buckling loads $(\lambda)$ of nonuniform beams 
TABLE 2: Nondimensional critical buckling loads of nonuniform columns with linearly varying stiffness distributions $S(X)=(1+X)$.

\begin{tabular}{lcccc}
\hline $\begin{array}{l}\text { Boundary } \\
\text { conditions }\end{array}$ & $\begin{array}{c}\text { Swenson } \\
{[2]}\end{array}$ & $\begin{array}{c}\text { GDQ }(N=11)(\text { Du et al. } \\
[48])\end{array}$ & $\begin{array}{c}\text { SBCGM }(N=11)(\text { Abumandour et al. } \\
[20])\end{array}$ & $\begin{array}{c}\text { Present proposed technique } \\
(N=11)\end{array}$ \\
\hline $\begin{array}{l}\text { Simple-simple } \\
\text { Clamped- }\end{array}$ & 14.3 & 14.511296 & 14.511255 & 14.511255 \\
clamped & - & 57.3453 & 57.391536 & 57.391536 \\
Clamped-simple & - & 29.4406 & 29.447984 & 29.447984 \\
\hline
\end{tabular}

TABLE 3: Nondimensional critical buckling loads of nonuniform columns with parabolically varying stiffness distributions $S(X)=(1+X)^{2}$.

\begin{tabular}{lccccc}
\hline Boundary conditions & Bleich [47] & Bert [36] & GDQ $(N=11)($ Du et al. [48]) & $\begin{array}{c}\text { SBCGM }(N=11) \\
\text { (Abumandour et al. [21]) }\end{array}$ & $\begin{array}{c}\text { Present proposed } \\
\text { technique }(N=11)\end{array}$ \\
\hline Simple-simple & 20.7923 & 27.455 & - & 20.8047 & 20.7943 \\
Clamped-clamped & - & - & 82.1043 & 81.9279 & 20.7943 \\
Clamped-simple & - & - & 41.9679 & 42.0828 & 81.9279 \\
\hline
\end{tabular}

TABLE 4: Nondimensional critical buckling loads of nonuniform columns without elastic foundations with linearly varying stiffness distributions $S(X)=(1+X)$.

\begin{tabular}{lcccccc}
\hline $\begin{array}{l}\text { Boundary } \\
\text { conditions }\end{array}$ & Bert [36] & Singh and Li [11] & Rosa and Franciosi [50] & Eisenberger [49] & Huang and Luo [51] $\begin{array}{c}\text { Present proposed } \\
\text { technique }(N=15)\end{array}$ \\
\hline Simple-simple & 15.31 & 14.505200922 & 14.58426 & 14.511249540 & 14.5112495395 & 14.5112495409638 \\
Clamped-clamped & - & 57.445246088 & - & 57.393956136 & 57.3939561351 & 57.3939565758955 \\
Clamped-simple & - & 29.495964646 & - & 29.448962806 & 29.4489628062 & 29.4489634582706 \\
\hline
\end{tabular}

TABLE 5: Nondimensional critical buckling loads of nonuniform columns without elastic foundations with parabolically varying stiffness distributions $S(X)=(1+X)^{2}$.

\begin{tabular}{lcccccc}
\hline $\begin{array}{l}\text { Boundary } \\
\text { conditions }\end{array}$ & Bleich [47] & Singh and Li [11] & Rosa and Franciosi [50] & Eisenberger [49] & Huang and Luo [51] $\begin{array}{c}\text { Present proposed } \\
\text { technique }(N=15)\end{array}$ \\
\hline $\begin{array}{l}\text { Simple-simple } \\
\text { Clamped- }\end{array}$ & 20.7923 & 20.791633301 & 21.21653 & 20.792288456 & 20.7922884552 & 20.7922891004959 \\
clamped & - & 82.228445608 & - & 81.923363881 & 81.9233636440 & 81.9233426420278 \\
Clamped-simple & - & 42.313450996 & - & 42.109176122 & 42.1091761225 & 42.1091391192221 \\
\hline
\end{tabular}

TABLE 6: Effects of elastic foundation parameters $\left[K_{1}, K_{2}, K_{3}\right]$ on the nondimensional critical buckling loads $(\lambda)$ for nonuniform columns with linearly varying stiffness distributions $S(X)=(1+X)$.

\begin{tabular}{|c|c|c|c|c|c|c|c|c|c|c|c|c|}
\hline \multirow{5}{*}{ Boundary conditions } & \multicolumn{12}{|c|}{ Buckling load $(\lambda)$} \\
\hline & \multicolumn{3}{|c|}{$\begin{array}{l}\text { Present proposed } \\
\text { technique }(N=15)\end{array}$} & \multicolumn{3}{|c|}{$\begin{array}{l}\text { Present proposed } \\
\text { technique }(N=15)\end{array}$} & \multicolumn{3}{|c|}{$\begin{array}{l}\text { Present proposed } \\
\text { technique }(N=15)\end{array}$} & \multicolumn{3}{|c|}{$\begin{array}{l}\text { Present proposed } \\
\text { technique }(N=15)\end{array}$} \\
\hline & \multicolumn{3}{|c|}{$\begin{array}{l}\text { Elastic foundation } \\
\text { parameters }\end{array}$} & \multicolumn{3}{|c|}{$\begin{array}{l}\text { Elastic foundation } \\
\text { parameters }\end{array}$} & \multicolumn{3}{|c|}{$\begin{array}{c}\text { Elastic foundation } \\
\text { parameters }\end{array}$} & \multicolumn{3}{|c|}{$\begin{array}{l}\text { Elastic foundation } \\
\text { parameters }\end{array}$} \\
\hline & $K_{1}$ & $K_{2}$ & $K_{3}$ & $K_{1}$ & $K_{2}$ & $K_{3}$ & $K_{1}$ & $K_{2}$ & $K_{3}$ & $K_{1}$ & $K_{2}$ & $K_{3}$ \\
\hline & 0.0 & 0.0 & 0.0 & 30 & 0.0 & 0.0 & 30 & 30 & 0.0 & 30 & 30 & 30 \\
\hline Simple-simple & \multicolumn{3}{|c|}{14.5112} & \multicolumn{3}{|c|}{17.5346} & \multicolumn{3}{|c|}{47.5346} & \multicolumn{3}{|c|}{50.1784} \\
\hline Clamped-clamped & \multicolumn{3}{|c|}{57.3940} & \multicolumn{3}{|c|}{59.6607} & \multicolumn{3}{|c|}{89.6607} & \multicolumn{3}{|c|}{92.6179} \\
\hline Clamped-simple & \multicolumn{3}{|c|}{29.4490} & \multicolumn{3}{|c|}{32.0561} & \multicolumn{3}{|c|}{62.0561} & \multicolumn{3}{|c|}{65.2047} \\
\hline
\end{tabular}

resting on two-layer elastic foundations, for three sets of boundary conditions. Fifteen nonuniformly spaced grid points were chosen by the previous relation. It can be observed from Tables 6 and 7 that the nondimensional critical buckling loads increase when the column rests on two-layer elastic foundations. 
TABLE 7: Effects of elastic foundation parameters $\left[K_{1}, K_{2}, K_{3}\right]$ on the nondimensional critical buckling loads $(\lambda)$ for nonuniform columns with parabolically varying stiffness distributions $S(X)=(1+X)^{2}$.

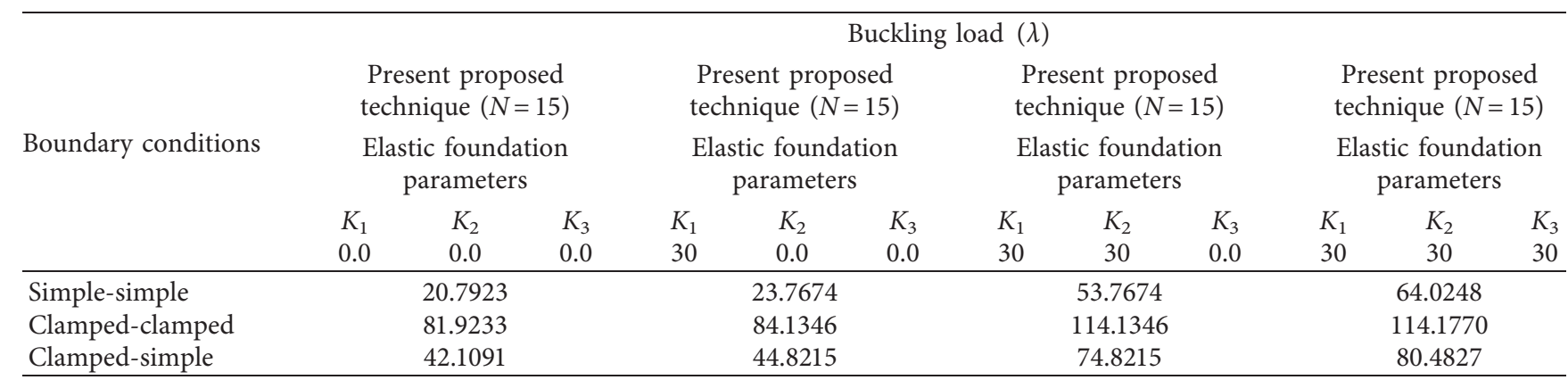

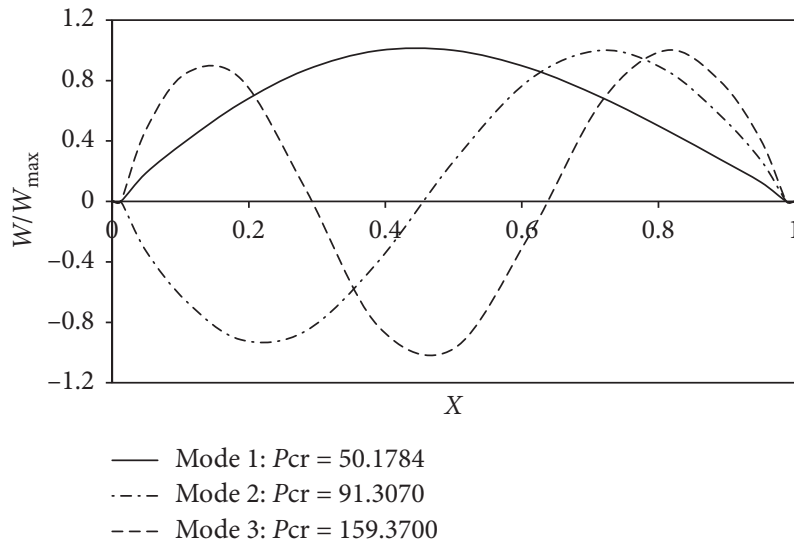

Figure 7: The first three mode shapes of nonuniform simplesimple supported column at foundation parameters $\left(K_{1}=30, K_{2}=30, K_{3}=30\right)$ with linearly varying stiffness distributions $S(X)=(1+X)$.

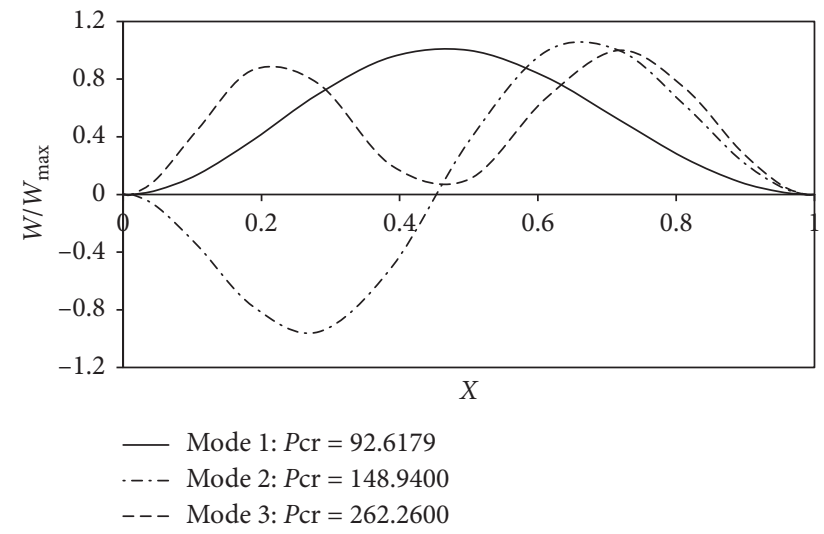

FIgURE 8: The first three mode shapes of nonuniform clampedclamped supported column at foundation parameters $\left(K_{1}=30, K_{2}=30, K_{3}=30\right)$ with linearly varying stiffness distributions $S(X)=(1+X)$.

Form Tables 6 and 7, when the inertia ratio (stiffness distributions) $S(X)$ is varying parabolically, the non-dimensional critical buckling loads of non-uniform columns increase in comparison when the inertia ratio varies linearly.

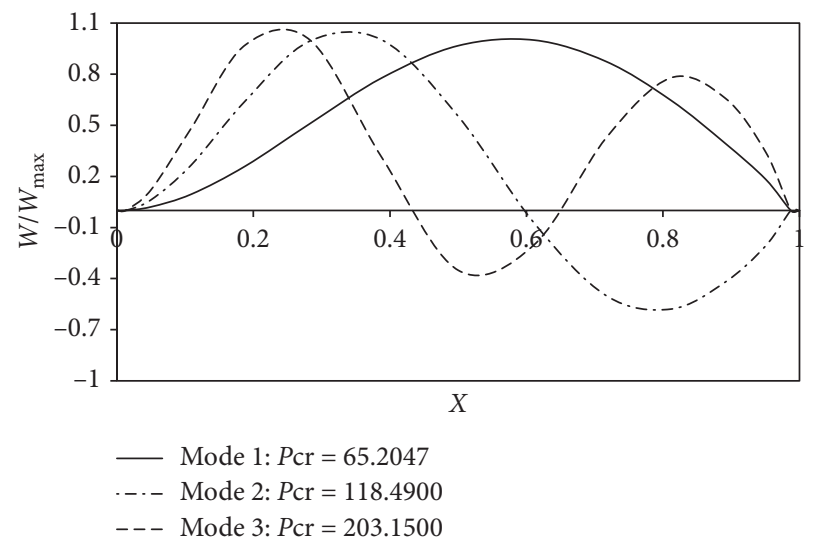

Figure 9: The first three mode shapes of nonuniform clampedsimple supported column at foundation parameters $\left(K_{1}=30, K_{2}=30, K_{3}=30\right)$ with linearly varying stiffness distributions $S(X)=(1+X)$.

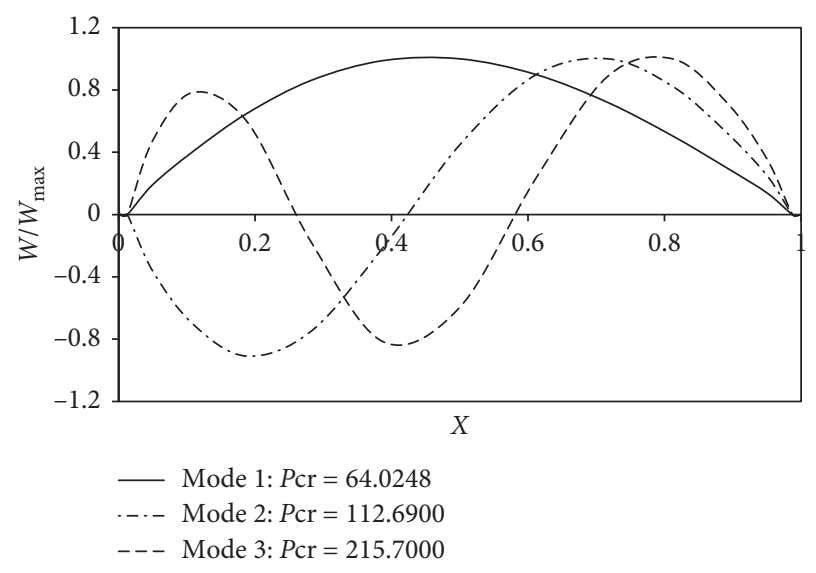

FIgUre 10: The first three mode shapes of nonuniform simplesimple supported column at foundation parameters $\left(K_{1}=30, K_{2}=30, K_{3}=30\right)$ with parabolically varying stiffness distributions $S(X)=(1+X)^{2}$.

The corresponding mode shapes are presented in Figures 7-12. Figures 7-9 show the first case of inertia ratio, and Figures 10-12 show the second case of inertia ratio. 


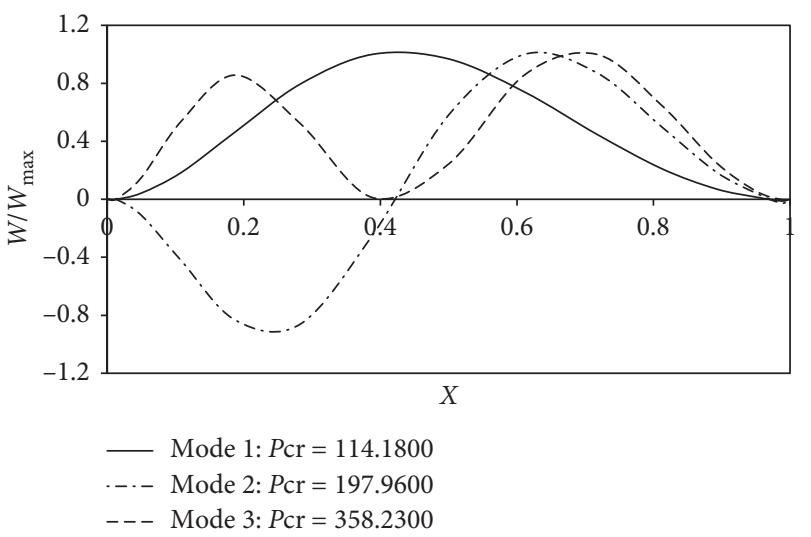

Figure 11: The first three mode shapes of nonuniform clamped-clamped supported column at foundation parameters $\left(K_{1}=\right.$ $\left.30, K_{2}=30, K_{3}=30\right)$ with parabolically varying stiffness distributions $S(X)=(1+X)^{2}$.

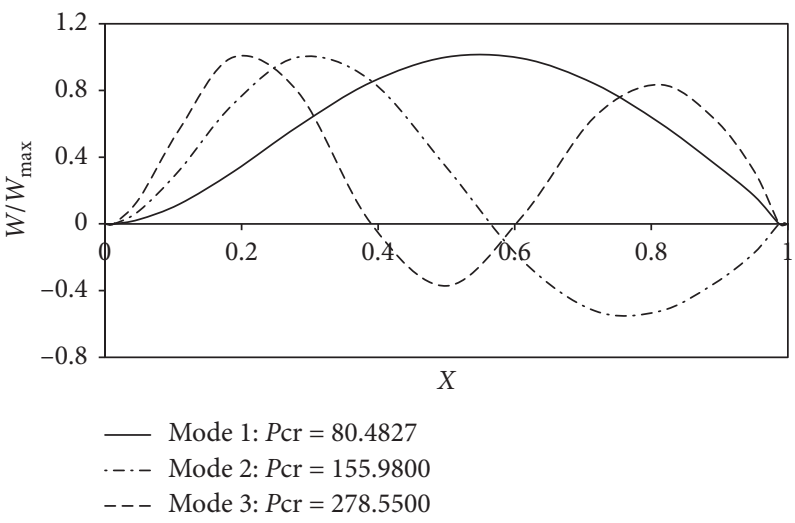

Figure 12: The first three mode shapes of nonuniform clamped-simple supported column at foundation parameters $\left(K_{1}=\right.$ $\left.30, K_{2}=30, K_{3}=30\right)$ with parabolically varying stiffness distributions $S(X)=(1+X)^{2}$.

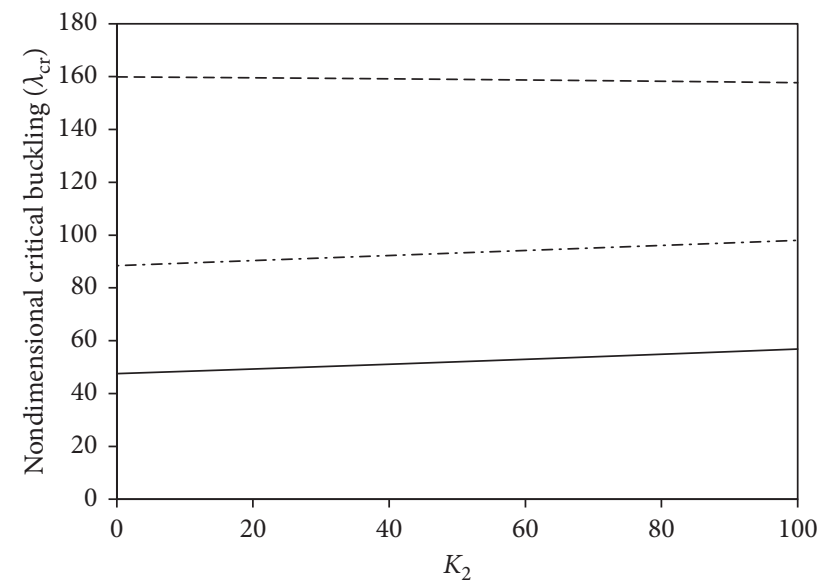

- Mode 1

Figure 13: The first three nondimensional buckling loads of nonuniform simple-simple supported columns with various $K_{2}$ at $\left(K_{1}=30, K_{3}=30\right)$ with linearly varying stiffness distributions $S(X)=(1+X)$.
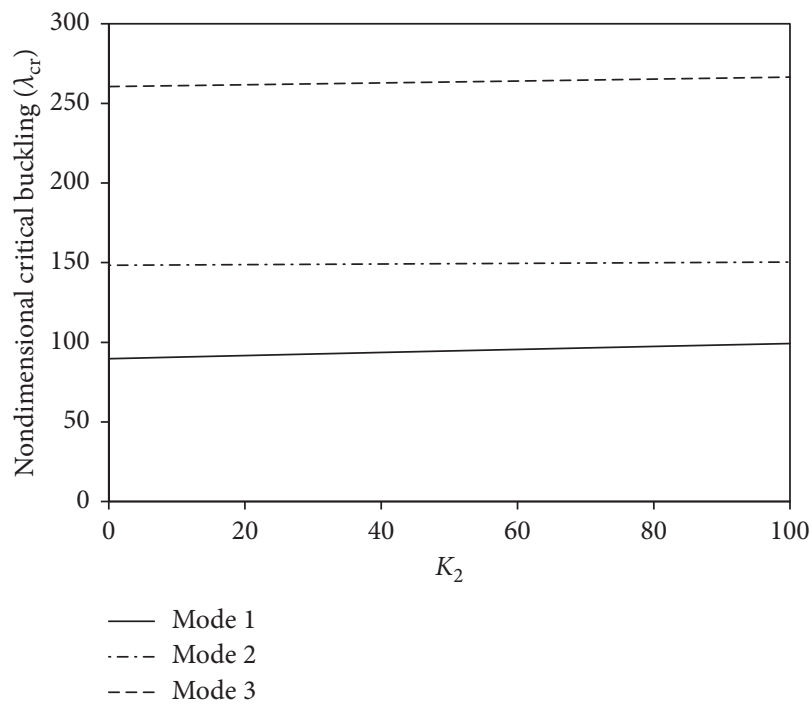

FIgURE 14: The first three nondimensional buckling loads of nonuniform clamped-clamped supported columns with various $K_{2}$ at $\left(K_{1}=30, K_{3}=30\right)$ with linearly varying stiffness distributions $S(X)=(1+X)$. 

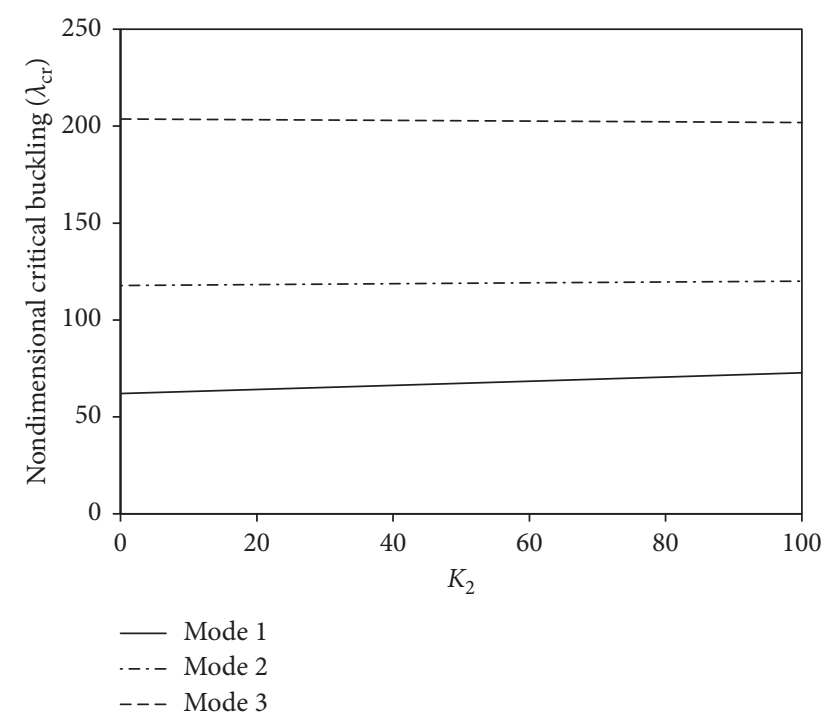

FIGURE 15: The first three nondimensional buckling loads of nonuniform clamped-simple supported columns with various $K_{2}$ at $\left(K_{1}=30, K_{3}=30\right)$ with linearly varying stiffness distributions $S(X)=(1+X)$.
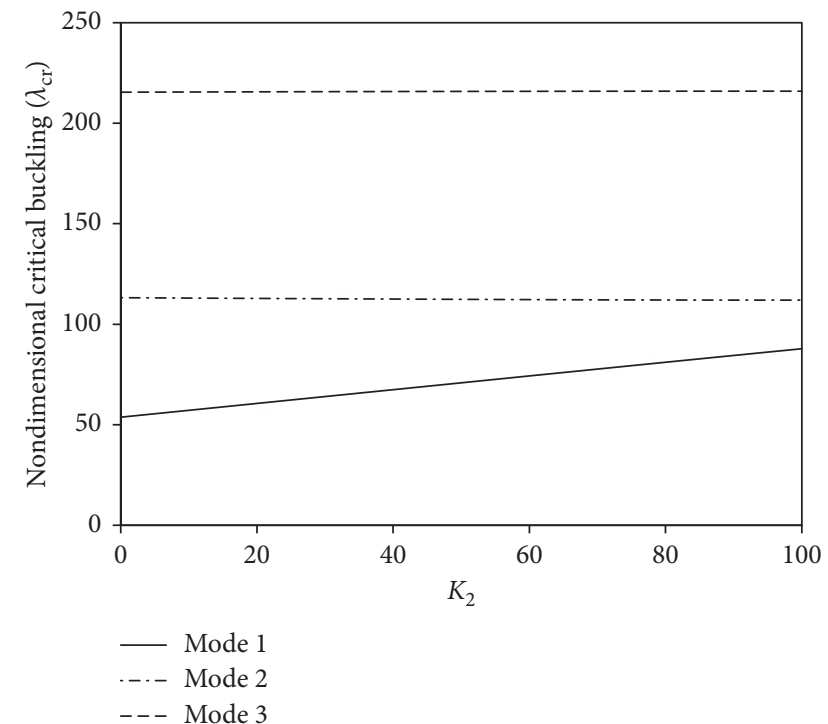

FIgURE 16: The first three nondimensional buckling loads of nonuniform simple-simple supported columns with various $K_{2}$ at $\left(K_{1}=30, K_{3}=30\right)$ with parabolically varying stiffness distributions $S(X)=(1+X)^{2}$.

To examine the effect of the nonlinear Winkler elastic foundation parameter " $K_{2}$," we fix the other values of elastic foundations " $K_{1}$ " and " $K_{3}$." Then, we draw " $K_{2}$ " versus the nondimensional critical buckling loads of nonuniform columns. It is clear that increasing the nonlinear elastic foundation " $\mathrm{K}_{2}$ " increases the nondimensional critical buckling loads of nonuniform columns. Figures 8-10 show the first case of inertia ratio, and Figures 11-13 show the second case of inertia ratio.

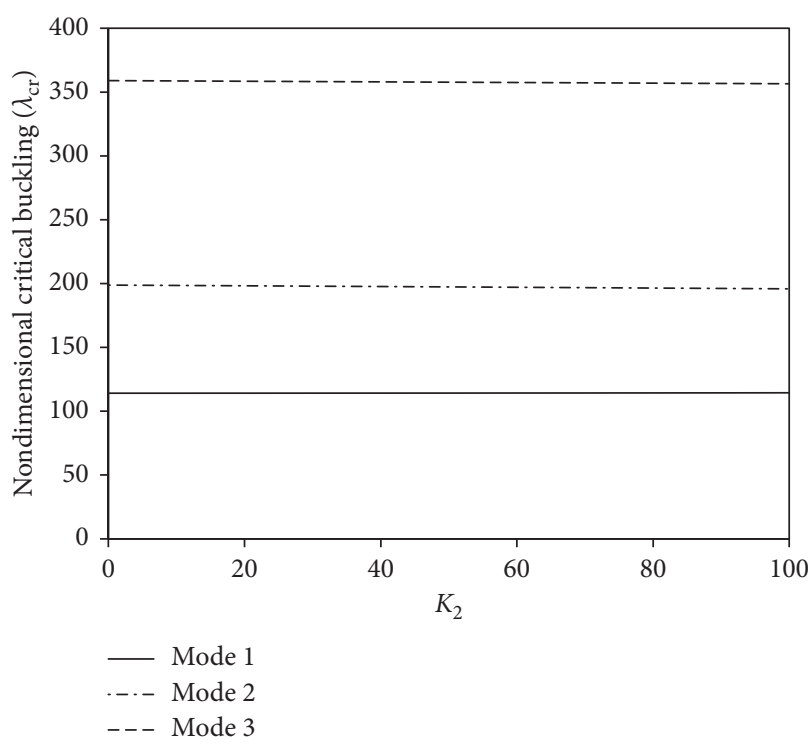

FIgURE 17: The first three nondimensional buckling loads of nonuniform clamped-clamped supported columns with various $K_{2}$ at $\left(K_{1}=30, K_{3}=30\right)$ with parabolically varying stiffness distributions $S(X)=(1+X)^{2}$.

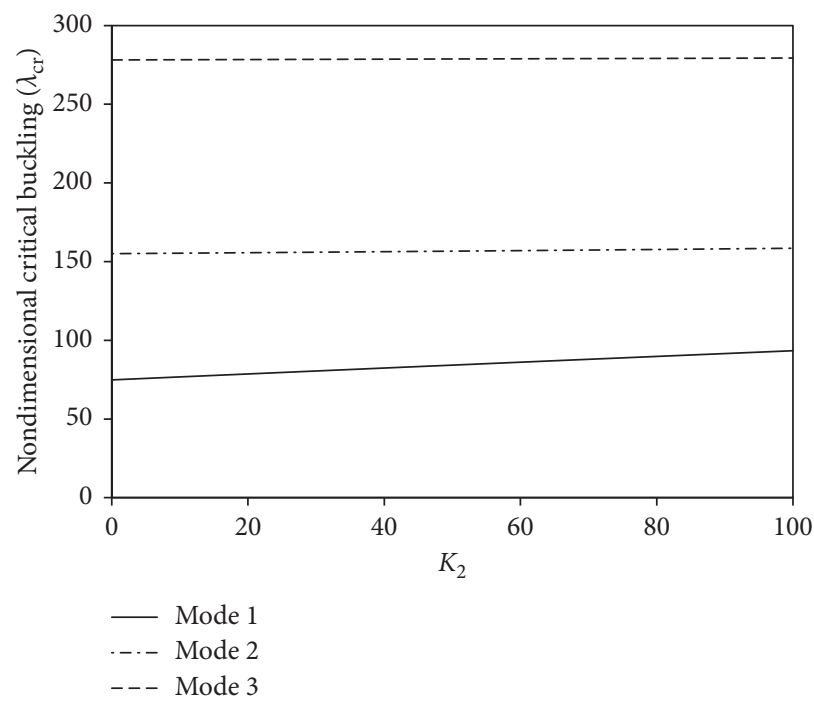

FIgUre 18: The first three nondimensional buckling loads of nonuniform clamped-simple supported columns with various $K_{2}$ at $\left(K_{1}=30, K_{3}=30\right)$ with parabolically varying stiffness distributions $S(X)=(1+X)^{2}$.

The corresponding Figures 13-18 present the effect of the nonlinear Winkler elastic foundation parameter " $K_{2}$ " (see Figures 13-15 for the first case of inertia ratio and Figures 16-18 for the second case of inertia ratio).

In addition, the effect of the nonlinearity term of Winkler elastic foundation $\left(K_{2}\right)$ on the nondimensional critical buckling loads of nonuniform columns for three sets of boundary conditions is studied, and the numerical results are plotted in Figures 19 and 20 with the special two cases of the stiffness distributions $S(X)=\left(1+\alpha_{1} X\right)^{\alpha_{2}}$, for 


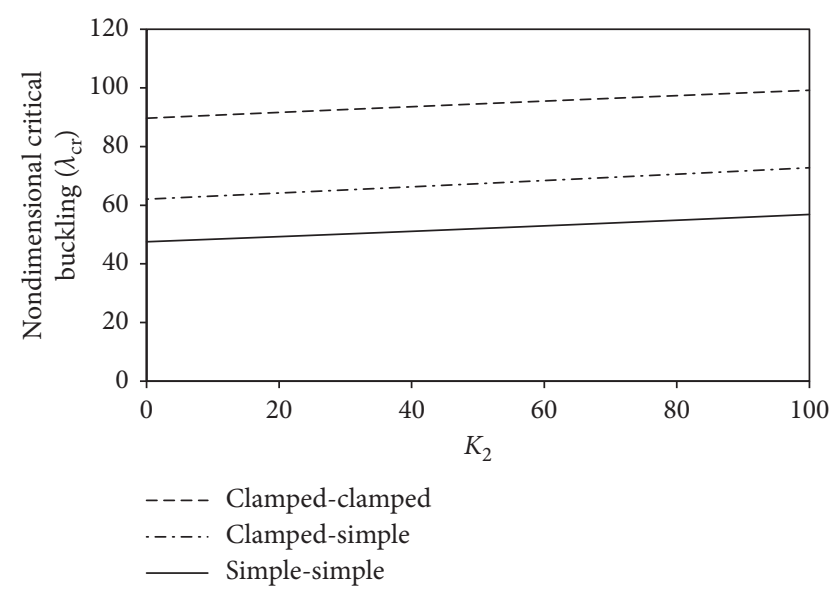

FIGURE 19: Effects of the nonlinear Winkler elastic foundation parameter " $K_{2}$ " on the nondimensional critical buckling loads $(\lambda)$ for nonuniform columns with linearly varying stiffness distributions $S(X)=(1+X)$.

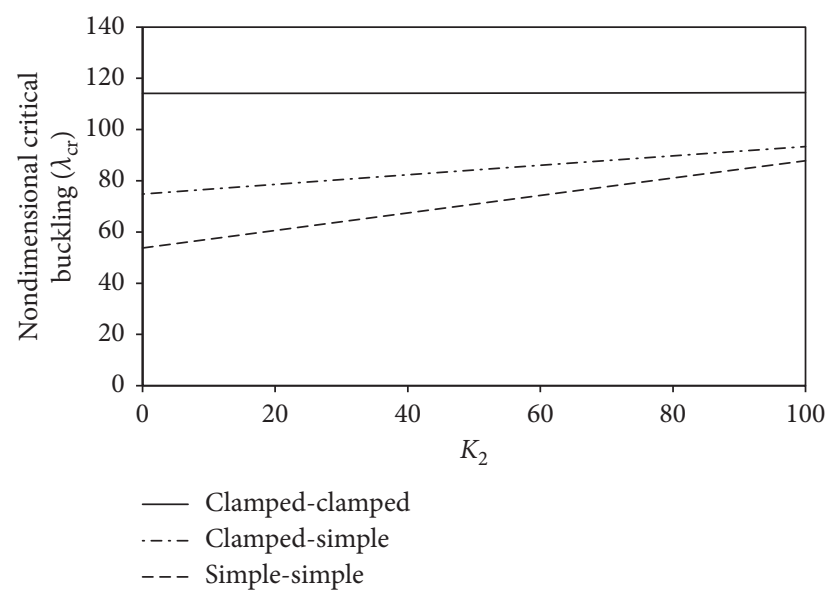

Figure 20: Effects of the nonlinear Winkler elastic foundation parameter " $K_{2}$ " on the nondimensional critical buckling loads $(\lambda)$ for nonuniform columns with parabolically varying stiffness distributions $S(X)=(1+X)$.

$\left[\alpha_{1}=1.0, \alpha_{2}=1.0\right]$ and $\left[\alpha_{1}=1.0, \alpha_{2}=2.0\right]$, respectively. From Figures 19 and 20, it can be seen that the nonlinear Winkler elastic foundation parameter " $K_{2}$ " has a strong influence on the nondimensional critical buckling loads.

\section{Conclusion}

A proposed approach of GDQ method has been presented to study the buckling behaviors of nonuniform columns resting on the two-layer elastic foundations (linear and nonlinear Winkler elastic foundation and the linear Pasternak elastic foundation). By using the proposed technique of GDQ method, we can determine the nondimensional critical buckling loads for any columns resting on any type of elastic foundations, linear or nonlinear. Several examples of computing the nondimensional critical buckling loads for uniform and nonuniform columns with and without elastic foundation for various boundary configurations have been presented. The validation of the proposed method has been approved by comparing our numerical results with the exact solutions and other available numerical results for uniform and nonuniform columns.

In this paper, we present three endeavors; the first one introduces simpler and efficient approach to simplify the procedure for determining the nondimensional critical buckling loads of nonuniform columns resting on the twolayer elastic foundations (linear and nonlinear Winkler elastic foundation and the linear Pasternak elastic foundation). A proposed approach is presented based on the GDQ method to solve the nonlinear problems. The proposed method is beneficial to optimum design of columns against buckling in engineering applications. The second endeavor explains the effects of the varying cross section area on the nondimensional critical buckling loads for columns with and without elastic foundation for three sets of boundary conditions, by the stiffness distributions as a polynomial of the form $S(X)=\left(1+\alpha_{1} X\right)^{\alpha_{2}}$. Finally, the third endeavor investigates the effect of the nonlinearity term of Winkler elastic foundation on the nondimensional critical buckling loads of nonuniform columns resting on elastic foundations (linear and nonlinear Winkler (normal) foundation and linear Pasternak (shear) foundation), under the three sets of boundary conditions.

This method is simple but efficient for solving similar dynamic problems and free vibration of uniform and nonuniform Euler-Bernoulli beams. By using the proposed technique of GDQ method to determine the nondimensional critical buckling loads for uniform and nonuniform columns with and without elastic foundations for various boundary conditions, the most important conclusions can be summarized as follows:

(i) When the inertia ratio (stiffness distributions) is varying parabolically, the non-dimensional critical buckling loads of non-uniform columns increase in comparison when the inertia ratio varies linearly.

(ii) The nondimensional critical buckling loads of nonuniform columns can be increased by supporting the columns by the elastic foundation.

(iii) The nondimensional critical buckling loads of nonuniform columns can be increased by increasing the nonlinear elastic foundation.

(iv) From the previous discussion, it can be seen that the nonlinear Winkler elastic foundation parameter has a strong influence on the nondimensional critical buckling loads.

\section{Data Availability}

The data used to support the findings of this study are included within the article.

\section{Conflicts of Interest}

The authors declare that there are no conflicts of interest with respect to this paper. 


\section{References}

[1] L. Euler, "Die altitudine colomnarum sub proprio pondere corruentium," Acta Academiae Scientiarum Imperialis Petropolitanae, vol. 1778, pp. 163-193, in Latin.

[2] G. W. Swenson, "Analysis of nununiform columns and beams by a simple D.C. Network analyzer," Journal of the Aeronautical Sciences, vol. 19, no. 4, pp. 273-275, 1952.

[3] A. Chajes, Principles of Structural Stability Theory, PrenticeHall, Englewood Cliffs, NJ, USA, 1974.

[4] A. G. Greenhill, "Determination of the greatest height consistent with stability that a vertical pole or mast can be made, and of the greatest height to which a tree of given Pro19 portions can grow," Proceedings of the Cambridge Philosophical Society, vol. 4, pp. 65-73, 1880.

[5] S. B. Coşkun, "Analysis of tilt-buckling of euler columns with varying flexural stiffness using homotopy perturbation method," Mathematical Modelling and Analysis, vol. 15, no. 3, pp. 275-286, 2010.

[6] A. Eryılmaz, M. Tarık Atay, S. B. Coşkun, and M. Başbük, "Buckling of Euler columns with a continuous elastic restraint via homotopy analysis method," Journal of Applied Mathematics, vol. 2013, Article ID 341063, 8 pages, 2013.

[7] S. B. Coşkun and B. Öztürk, "Elastic stability analysis of euler columns using analytical approximate techniques," Advances in Computational Stability Analysis, IntechOpen Limited, vol. 6, no. 1, pp. 115-132, London, UK, 2012.

[8] M. H. Taha and S. Abohadima, "Mathematical model for vibrations of non-uniform flexural beams," Engineering Mechanics, vol. 15, no. 1, pp. 3-11, 2008.

[9] S. B. Coşkun and M. T. Atay, "Determination of critical buckling load for elastic columns of constant and variable cross-sections using variational iteration method," Computers \& Mathematics with Applications, vol. 58, no. 11-12, pp. 2260-2266, 2009.

[10] M. T. Atay and S. B. Coşkun, "Elastic stability of Euler columns with a continuous elastic restraint using variational iteration method," Computers \& Mathematics with Applications, vol. 58, no. 11-12, pp. 2528-2534, 2009.

[11] K. V. Singh and G. Li, "Buckling of functionally graded and elastically restrained non-uniform columns," Composites Part B: Engineering, vol. 40, no. 5, pp. 393-403, 2009.

[12] Y. Huang and X.-F. Li, "An analytic approach for exactly determining critical loads of buckling of nonuniform columns," International Journal of Structural Stability and Dynamics, vol. 12, no. 4, p. 1250027, 2012.

[13] D. Z. Yankelevsky, M. Eisenberger, and M. A. Adin, "Analysis of beams on nonlinear winkler foundation," Computers \& Structures, vol. 31, no. 2, pp. 287-292, 1989.

[14] A. D. Kerr, "Elastic and viscoelastic foundation models," Journal of Applied Mechanics, vol. 31, no. 3, pp. 491-498, 1964.

[15] M. Eisenberger and J. Clastornik, "Vibrations and buckling of a beam on a variable Winkler elastic foundation," Journal of Sound and Vibration, vol. 115, no. 2, pp. 233-241, 1987.

[16] P. Malekzadeh and G. Karami, "A mixed differential quadrature and finite element free vibration and buckling analysis of thick beams on two-parameter elastic foundations," Applied Mathematical Modelling, vol. 32, no. 7, pp. 1381-1394, 2008.

[17] S. B. Coşkun, "Determination of critical buckling loads for euler columns of variable flexural stiffness with a continuous elastic restraint using homotopy perturbation method,"
International Journal of Nonlinear Sciences and Numerical Simulation, vol. 10, no. 2, pp. 191-198, 2009.

[18] R. M. Abumandour, M. Kamel, and M. Nassar, "Application of the GDQ method to vibration analysis," International Journal of Mathematics and Computational Science, vol. 1, no. 5, pp. 242-249, 2015.

[19] R. M. Abumandour, M. Kamel, and S. Bichir, "Application of the GDQ method to structural analysis," International Journal of Mathematics and Computational Science, vol. 2, no. 1, pp. 8-19, 2016.

[20] R. M. Abumandour, I. M. Eldesoky, M. A. Safan, R. M. RizkAllah, and F. A. Abdelmgeed, "Deflection of non-uniform beams resting on a non-linear elastic foundation using (GDQM)," International Journal of Structural and Civil Engineering Research, vol. 6, no. 1, pp. 52-56, 2017.

[21] R. M. Abumandour, I. M. Eldesoky, M. A. Safan, R. M. RizkAllah, and F. A. Abdelmgeed, "Vibration analysis of nonuniform beams resting on two layer elastic foundations under axial and transverse load using (GDQM)," International Journal of Mechanical Engineering and Applications, vol. 5, no. 2, p. 70, 2017.

[22] G. Kerschen, K. Worden, A. F. Vakakis, and J.-C. Golinval, "Past, present and future of nonlinear system identification in structural dynamics," Mechanical Systems and Signal Processing, vol. 20, no. 3, pp. 505-592, 2006.

[23] A. Afsharfard and A. Farshidianfar, "Finding the buckling load of non-uniform columns using the iteration perturbation method," Theoretical and Applied Mechanics Letters, vol. 4, no. 4, Article ID 041011, 2014.

[24] A. Nayfeh, Introduction to Perturbation Techniques, Wiley, Hoboken, NJ, USA, 1981.

[25] A. H. Nayfeh, Perturbation Methods, Wiley Classics Library edn. John Wiley \& Sons, Hoboken, NJ, USA, 2000.

[26] D. Adair, A. Ibrayev, A. Tazabekova, and J. R. Kim, "Free vibrations with large amplitude of axially loaded beams on an elastic foundation using the Adomian modified decomposition method," Shock and Vibration, vol. 2019, Article ID 3405075, 10 pages, 2019.

[27] I. M. Eldesoky, M. H. Kamel, R. M. Hussien, and R. M. Abumandour, "Numerical study of unsteady MHD pulsatile flow through porous medium in an artery using generalized differential quadrature method (GDQM)," International Journal of Materials, Mechanics and Manufacturing, vol. 1, no. 2, pp. 200-206, 2013.

[28] I. Eldesoky, M. Kamel, and R. Abumandour, "Numerical solution of unsteady MHD pulsating flow of couple stress fluid through porous medium between permeable beds using differential quadrature method (DQM)," The International Conference on Mathematics and Engineering Physics, vol. 7, no. 6, pp. 1-28, 2014.

[29] S. H. Chen and Y. K. Cheung, "A modified lindstedt-poincare method for a strongly non-linear two degree-of-freedom system," Journal of Sound and Vibration, vol. 193, no. 4, pp. 751-762, 1996.

[30] T. C. Fung, "Solving initial value problems by differential quadrature method?part 2: second- and higher-order equations," International Journal for Numerical Methods in Engineering, vol. 50, no. 6, pp. 1429-1454, 2001.

[31] T. C. Fung, "Solving initial value problems by differential quadrature method?part 1: first-order equations," International Journal for Numerical Methods in Engineering, vol. 50, no. 6, pp. 1411-1427, 2001.

[32] C. Shu, Q. Yao, and K. Yeo, "Block-marching in time with DQ discretization: an efficient method for time-dependent 
problems," Computer Methods in Applied Mechanics and Engineering, vol. 191, no. 41-42, pp. 4587-4597, 2002.

[33] J. Liu and X. Wang, "An assessment of the differential quadrature time integration scheme for nonlinear dynamic equations," Journal of Sound and Vibration, vol. 314, no. 1-2, pp. 246-253, 2008.

[34] R. Bellman and J. Casti, "Differential quadrature and longterm integration," Journal of Mathematical Analysis and Applications, vol. 34, no. 2, pp. 235-238, 1971.

[35] R. Bellman, B. G. Kashef, and J. Casti, "Differential quadrature: a technique for the rapid solution of nonlinear partial differential equations," Journal of Computational Physics, vol. 10 , no. 1, pp. 40-52, 1972.

[36] C. W. Bert, S. K. Jang, and A. G. Striz, "Two new approximate methods for analyzing free vibration of structural components," AIAA Journal, vol. 26, no. 5, pp. 612-618, 1988.

[37] C. Shu, Differential Quadrature and its Application in Engineering, Springer-Verlag, Berlin, Germany, 2000.

[38] Z. Zong and Y. Y. Zhang, Advanced Differential Quadrature Methods, CRC Press, Boca Raton, FL, USA, 2009.

[39] C. Shu and B. E. Richards, "High resolution of natural convection in a square cavity by generalized differential quadrature," in Proceedings of 3rd International Conference on Advanced in numerical Methods in Engineering: Theory and Applications, vol. 2, pp. 978-985, Swansea, Wales, 1990.

[40] C. Shu, Generalized differential-integral quadrature and application to the simulation of incompressible viscous flows including parallel computation, Ph.D. thesis, University of Glasgow, Glasgow, Scotland, 1991.

[41] J. R. Quan and C. T. Chang, "New insights in solving distributed system equations by the quadrature method-I. Analysis," Computers \& Chemical Engineering, vol. 13, no. 7, pp. 779-788, 1989.

[42] H. Chang, M. K. Lim, and R. M. Lin, "Application of generalized differential quadrature to vibration analysis," Journal of Sound and Vibration, vol. 181, no. 2, pp. 279-293, 1995.

[43] C. Shu and H. Du, "A generalized approach for implementing general boundary conditions in the GDQ free vibration analysis of plates," International Journal of Solids and Structures, vol. 34, no. 7, pp. 837-846, 1997.

[44] C. Shu and C. M. Wang, "Treatment of mixed and nonuniform boundary conditions in GDQ vibration analysis of rectangular plates," Engineering Structures, vol. 21, no. 2, pp. 125-134, 1999.

[45] H. Du, M. K. Lim, and R. M. Lin, "Application of generalized differential quadrature to structural problems," Journal of Sound and Vibrations, vol. 181, pp. 279-293, 1994.

[46] A. L. Newberry, C. W. Bert, and A. G. Striz, "Nonintegerpolynomial flnite-element analysis of column buckling," Journal of Structural Engineering, vol. 113, no. 4, pp. 873-878, 1987.

[47] H. Bleich, Buckling Strength of Metal Structures, McGrawHill, New York, NY, USA, 1952.

[48] C. W. Bert, "Improved technique for estimating buckling loads," Journal of Engineering Mechanics, vol. 110, no. 12, pp. 1655-1665, 1984.

[49] M. Eisenberger, "Buckling loads for variable cross-section members with variable axial forces," International Journal of Solids and Structures, vol. 27, no. 2, pp. 135-143, 1991.

[50] D. M. A. Rosa and C. Franciosi, "The optimized Rayleigh method and mathematica in vibrations and buckling problems," Journal of Sound and Vibration, vol. 191, no. 5, pp. 795-808, 1996.

[51] Y. Huang and Q.-Z. Luo, "A simple method to determine the critical buckling loads for axially inhomogeneous beams with elastic restraint," Computers \& Mathematics with Applications, vol. 61, no. 9, pp. 2510-2517, 2011. 